\title{
The Effect of the Mixture of Nonionic Surfactant and Bioactive Agent for Surfactant-enhanced Soil Flushing (SESF) of TCB Contaminated Soil
}

\author{
Dal-Heui Lee ${ }^{1 *} \cdot$ Heuy Nam Cho ${ }^{2} \cdot$ Sung-Lae Chung ${ }^{3}$ \\ ${ }^{1,3}$ Sung Ji Engineering Co., Ltd. \\ ${ }^{2}$ G\& G Technology Co., Ltd.
}

\begin{abstract}
The objective of this study was to find the effect of the mixture of the nonionic surfactant and bioactive agent that solubilizes trichlorobenzene (TCB) present as a contaminant for surfactant-enhanced soil flushing (SESF). Three different nonionic surfactants and two different bioactive agents were obtained from four companies. Separate funnel experiments and shaker table agitation / centrifugation experiments were used for the test. Based on the separate funnel experimental results, three suitable mixture agents (APG + OSE, Brij 35 + MOSE, T-Maz 60+ MOSE) were selected. In the shaker table agitation / centrifugation experiments, these three different mixture agents were reduced to one (T-Maz 60 + MOSE). The maximum removal $(95 \%)$ of TCB was obtained using a mixture of the nonionic surfactant and bioactive agent. Therefore, the used test methods and results can be used for SESF.
\end{abstract}

Key words : SESF, TCB, Nonionic surfactants, Bioactive agents, Maximum removal

\section{Introduction}

Dense non-aqueous phase liquids (DNAPLs), such as trichlorobenezene (TCB), have posed a threat to the environment in industrial areas of Korea (Lee et al., 2001; Chung and Lee, 2012). Under normal flow regimes, this DNAPL phase is immobile and often represents a long-term source of aquifer contamination as it slowly dissolves into the groundwater (Deshpande et al., 1999; Wang and Mulligan, 2004). Surfactants (surface active agents) and / or bioactive agents may aid in the remediation of subsoil and aquifers contaminated with DNAPL (Lee et al., 2001; Mulligan and Gibbs, 1993). Surfactants and /or bioactive agents can be used to vastly increase the solubility of the DNAPL in water as well as lower the interfacial tension at the water- DNAPL interface (Rosen, 1989; Rouse et al., 1993; Wang and Mulligan, 2004).

Surfactants can be classified according to the nature of the hydrophilic portion of the molecule: anionic, cationic, nonionic, and zwitterionic (Rosen, 1989). Nonionic surfactants generally have smaller critical micelle concentration (CMC) values than ionic surfactants and are known to be good solubilizers of hydrophobic substances (Ang and Abdul, 1994). Generally, cationic surfactants are not selected in remediation works because of toxicity and strong complexion with anionic soil mineral surfaces (Paria and Khilar, 2004). Also, anionic surfactants may form precipitates with groundwater cations, and thereby cause reduction in soil hydraulic conductivity by blocking pores (Rouse et al., 1993; Lee et al., 2002; Chu and Kwan, 2003).

Abdul et al. (1990) evaluated the suitability of ten surfactants for washing automatic transmission fluid (ATF) from sand. They measured the surface tension of the surfactant and also conducted batch tests for solubilization capacity. The most effective surfactant was Witconol SN70 (alkyl polyoxyethylene glycol, a nonionic surfactant). DOSL (diphenyl oxide disulfonates, an anionic surfactant) was also a good surfactant for the removal of chlorinated hydrocarbon in the column test and the pilot test (Cort et al., 2002). In another surfactant selection study, using a separate funnel experiment of solubility, Fountain et al. (1991) evaluated 100 surfactants for washing PCE (tetrachloroe-

*Corresponding author:dalheui@yonsei.ac.kr

Received:2013. 10.6 Reviewed:2014. 1.23 Accepted:2014.1.23

Discussion until : 2014. 6. 30 
thylene) from sand. The most effective surfactant was the $1: 1$ volume mixture of Rexophos 25/27 (anionic) and TDet N-9.5 (nonionic). These results show that the effectiveness of the surfactant differs depending on the specific organic contaminant.

The surfactant-enhanced soil flushing (SESF) extracts contaminants from soil matrices using a liquid medium such as an aqueous surfactant solution and/or bioactive agent solution (Fountain et al., 1991; Mulligan et al., 1999). SESF system is a combination of physical separation and chemical treatment, including physical separation techniques and extraction techniques. Also, SESF technology may be designed either to remove DNAPL or/and simultaneously act as an augmentation for existing technologies such as pump-and-treat systems (Wang and Mulligan, 2004). A major concern related to the effectiveness of SESF is surfactant losses. Nonionic surfactants seem to be less susceptible than ionic (anionic/cationic) surfactants to precipitation losses due to an increase in their solubility and steric constraints (Rosen, 1989; Lee et al., 2008). Therefore, the objective of this study was to find the effect of the mixture of the nonionic surfactant and bioactive agent that solubilizes TCB present as a contaminant for SESF.

\section{Materials and methods}

\subsection{Materials}

The three surfactants and two bioactive agents were used as received. The surfactants and bioactive agents, along with their relevant properties, are listed in Table 1 and Table 2 , respectively. The used bioactive agents consist of lipopolysaccharides, phospholipids, and fatty acids. They are readily biodegradable and are used for general-purpose cleaning. Deionized water was used in preparing surfactant and bioactive agent samples.

The material used as model soil required high permeability, low cation exchange capacity (CEC), and low total organic carbon content. Ottawa sand was selected because it met these criteria and because of its uniformity and simple mineralogy. It was obtained from the U. S. Silica Company (Ottawa, IL). The mean grain diameter of Ottawa sand is $0.45 \mathrm{~mm}$, and the specific surface area is $0.007 \mathrm{~m}^{2} / \mathrm{g}$ (Lee et al., 2001). 1,2,4-trichlorobenzene (TCB) was employed as a DNAPL model substance representative of aromatic chlorinated solvents, and is commonly reported as a groundwater contaminant (Lee et al., 2001). TCB is not effectively removed by water pump-and-treat cleanup technology because of its hydrophobic nature. TCB

Table 1. Properties of surfactants used in this study

\begin{tabular}{lrlcl}
\hline \hline Trade Name Chemical Name & HLB $^{\mathrm{a}}$ & $\mathrm{CMC}^{\mathrm{b}}$ & Molecular Formula & Type Manufacturer \\
\hline APG Alkyl Polyglucoside & 9 & 0.004 & N/A & Nonionic Henkel Korea, Korea \\
Brij 35 POE(23) Lauryl Ether & 11 & 0.0099 & $\mathrm{C}_{12}\left(\mathrm{CH}_{2} \mathrm{CH}_{2} \mathrm{O}\right)_{23}$ & Nonionic Yakuri Chemicals, Japan \\
T-Maz 60 POE (20) Sorbitan Monostearate & 14 & 0.023 & $\mathrm{C}_{18} \mathrm{H}_{34} \mathrm{O}_{2} \mathrm{C}_{6} \mathrm{H}_{10} \mathrm{O}_{4}\left(\mathrm{CH}_{2} \mathrm{CH}_{20}\right)_{20}$ & Nonionic PPG/Mazer Chemicals, USA \\
\hline
\end{tabular}

${ }^{\mathrm{a}}=$ Hydrophilic-lipophilic balance

$\mathrm{b}=$ Critical micelle concentration (unit: $\mathrm{mM}$ ). Data provided by the surfactant manufacturers

$\mathrm{c}=$ polyoxyethylene

$\mathrm{N} / \mathrm{A}=$ Not Available

Table 2. Properties of bioactive agents used in this study

\begin{tabular}{ccccc}
\hline \hline Trade Name & Surface Tension & Interfacial Tension & Main Composition & Manufacturer \\
\hline \multirow{2}{*}{ OSE } & & & Lipopolysaccharides & \\
& \multirow{2}{*}{$30 \mathrm{mN} / \mathrm{m}$} & $1 \mathrm{mN} / \mathrm{m}$ & Phospholipids & WISCO, Korea \\
& & Fatty acids & Nutrient \\
& & Lipopolysaccharides & \\
MOSE & \multirow{2}{*}{$20 \mathrm{mN} / \mathrm{m}$} & Phospholipids & WISCO, Korea \\
& & Fatty acids & Enzyme \\
& & Nutrient & \\
\hline
\end{tabular}


(spectrophotometric grade) was obtained from Aldrich Chemical. Characteristics of TCB are shown in Table 3.

Prior to use, the Ottawa sand (20-30 mesh) was rinsed with $0.1 \mathrm{~N} \mathrm{HCl}$ and deionized water. Contamination of soil was achieved by dissolving $5 \mathrm{~mL}$ of the TCB in $20 \mathrm{~mL}$ of hexane, and slowly adding the mixture to $100 \mathrm{~g}$ of the soil. After mixing by a shaker table for 10 minutes at $1000 \mathrm{rpm}$, the wet soil mixture was then placed in a hood at $30^{\circ} \mathrm{C}$, and the hexane and TCB was allowed to evaporate for 10 minutes. The mixture was agitated several times during this process (Lee, 1999).

\subsection{Separate funnel experiments}

This series of experiments provided a rapid, qualitative, and fairly reliable means of determining which surfactant

Table 3. Characteristics of the used contaminant

\begin{tabular}{lc}
\hline \hline Chemical Name & $\begin{array}{c}\text { 1,2,4-Trichloroben- } \\
\text { zene (TCB) }\end{array}$ \\
\hline Formula & $\mathrm{C}_{6} \mathrm{H}_{3} \mathrm{Cl}_{3}$ \\
Molecular Weight $(\mathrm{g} / \mathrm{mol})$ & 181.45 \\
Density $\left(\mathrm{g} / \mathrm{mL}\right.$ at $\left.25^{\circ} \mathrm{C}\right)$ & 1.454 \\
Boiling Point $\left({ }^{\circ} \mathrm{C}\right)$ & 214 \\
Melting Point $\left({ }^{\circ} \mathrm{C}\right)$ & 16 \\
Purity & $>99 \%$ \\
CAS Number & $120-82-1$ \\
Aqueous Solubility $(\mathrm{mg} / \mathrm{L})$ & 48.8 \\
Log Kow(octanol-water partition coefficient) & 4.02 \\
Viscosity $(\mathrm{cP})$ & 0.83 \\
Liquid-Water Interfacial Tension (dyne/cm) & 45 \\
Liquid-Air Interfacial Tension (dyne/cm) & 25 \\
\hline
\end{tabular}

and/or bioactive agent are good solubilizers. Experimental procedures were as follows: $100 \mathrm{~mL}$ of a $4 \%(\mathrm{v} / \mathrm{v})$ or $4 \%$ $(w / v)$ of each aqueous surfactant solution and/or bioactive agent were placed in a $250 \mathrm{~mL}$ separate funnel and an initial $1 \mathrm{~mL}$ of TCB was added. The funnel was then shaken gently for 60 seconds and left to settle for two hours. If the entire volume of TCB was solubilized, then another $1 \mathrm{~mL}$ of TCB was added and the funnel was shaken again. If any of the first $1 \mathrm{~mL}$ remained or if an emulsion was present, the funnel was shaken again for 60 seconds and then again set aside during for two hours (Lee et al., 2001; Lee et al., 2002).

This process continued for six hours, after which the funnels were left undisturbed for the remainder of the 24hour period. The experiment ended after 24 hours, and the results recorded. This process was repeated three times for each eleven different cases (Table 4).

\subsection{Shaker table agitation / centrifugation experiments}

These experiments were conducted to select suitable surfactants and/or bioactive agents which could solubilize/ extract the TCB compound from contaminated Ottawa sand. The concentration of TCB of Ottawa sand was $5 \mathrm{mg} /$ $\mathrm{kg}$. Experimental procedures were as follows: $80 \mathrm{~g}$ of contaminated Ottawa sand with $250 \mathrm{~mL}$ of $4 \%$ (v/v) (or $2 \%$ $(\mathrm{v} / \mathrm{v})+2 \%(\mathrm{v} / \mathrm{v})$ in mixing) aqueous surfactant solutions and/or bioactive agent were placed in $500 \mathrm{~mL}$ Telflon screw cap jars. The contaminated Ottawa sand and aqueous surfactant solution and/or bioactive agent were mixed in a

Table 4. The results of separatory funnel experiments

\begin{tabular}{cccl}
\hline \hline $\begin{array}{c}\text { Selected } \\
\text { Agents } \\
\text { Order }\end{array}$ & $\begin{array}{c}\text { Amount TCB } \\
\text { Added (ml) }\end{array}$ & $\begin{array}{c}\text { Estimated Amount } \\
\text { Solubilized (ml) }\end{array}$ & Characteristics after 24 hours, Decesion \\
APG & 2.5 & 2.5 & Very clear liquid formed, ineffective \\
Brij 35 & 2 & 2 & Very clear liquid formed, ineffective \\
T-Maz 60 & 2.5 & 2.5 & Light milky emulsion, ineffective \\
OSE & 1 & 0.5 & Very clear liquid formed, ineffective \\
MOSE & 1.5 & 1 & No foaming with milky color, ineffective \\
APG + OSE & 3.5 & 3.5 & Very clear liquid formed, passing \\
APG + MOSE & 2.5 & 2.5 & Little foaming, ineffective \\
Brij 35 + OSE & 2.5 & 2.5 & Light milky emulsion, ineffective \\
Brij 35 + MOSE & 3.5 & 3.5 & Very clear liquid formed, passing \\
T-Maz 60 + OSE & 2.5 & 2.5 & Light milky emulsion, ineffective \\
T-Maz 60 + MOSE & 3.5 & 3.5 & Very clear liquid formed, passing \\
\hline
\end{tabular}


shaker table at $200 \mathrm{rpm}$ and 50 minutes. The jar was then centrifuged at $2000 \mathrm{rpm}$ for 5 minutes to separate the aqueous and Ottawa sand phases. The liquid was decanted, $250 \mathrm{~mL}$ of deionized water was added to the soil, and the jar was shaken again for 50 minutes. The process was repeated until one surfactant and/or bioactive agent wash and two deionized water rinses were completed. Leachates were collected after each step and analyzed for the contaminant (Lee et al., 2001; Lee et al., 2002).

\subsection{Analytical methods}

The TCB in aqueous samples was extracted by solvent extraction with hexane using the standard separate funnel method 3510 and analyzed by gas chromatography with the split / splitless injection system (Hewlett Packard Model 5890 series II). The TCB was analyzed according to U.S. EPA standard methods using gas chromatography equipped with a flame ionization detector at the on-site laboratory. Prior to the analysis of sample extracts, the response factor and linearity of detection for the internal standard and contaminant were determined. The main criteria for selecting an internal standard are water solubility, chromatographic similarity to analyzed substance, and structure. The compound selected was ethyl benzene. After having calculated the response factor, a calibration graph was prepared. The quantitative determination of contaminant concentration was based on these internal standard reference compounds, so that the sample peak areas were compared with those of their respective internal standards (Lee et al., 2001). New standard curves were prepared after approximately 15-20 injections.

\section{Results and Discussion}

\subsection{Separate funnel experiments}

In these experiments, it was noted how much TCB was taken into an emulsion- solution before a separate phase was observed (e.g. TCB separated or a heavy emulsion / TCB phase separated from the rest of the solution). APG, Brij 35, T-Maz 60, OSE, MOSE, APG + MOSE, Brij $35+$ OSE, and T-Maz 60+ OSE were not able to solubilize at least $3 \mathrm{~mL}$ of TCB and were considered ineffective, while those that solubilized more than this amount were given a "passing" grade and then subjected to further screening techniques (Table 4). APG + OSE, Brij $35+$ MOSE, and TMaz $60+$ MOSE were relatively good solubilizer for TCB based on the separate funnel experiments. These eleven different surfactants and/or bioactive agents were reduced to three in the separate funnel experiments (Table 5). These were then used in a variety of other experiments, such as shaker table agitation/centrifugation experiments, which are discussed later. Emulsion and foam formation can create problems, but were not found in separate funnel experiments. Also, nonionic surfactants may undergo phase separation as the surfactant concentration increases (Rosen, 1989; Martel and Gelinas, 1996; Mulligan et al., 1999). This phase separation is related to the cloud point temperature of most nonionic surfactants. We did not

Table 5. The results of the TCB removal (\%) in the shaker table and centrifugation experiments

\begin{tabular}{|c|c|c|c|}
\hline $\begin{array}{l}\text { Selected } \\
\text { Agents } \\
\text { Order }\end{array}$ & $1^{\text {st }}$ Test by Agent & $1^{\text {st }}$ Test by Agent + one rinsing & $1^{\text {st }}$ Test by Agent + two rinsing \\
\hline APG & 60 & 62 & 63 \\
\hline Brij 35 & 65 & 66 & 67 \\
\hline T-Maz 60 & 65 & 65 & 68 \\
\hline OSE & 40 & 40 & 40 \\
\hline MOSE & 50 & 51 & 52 \\
\hline $\mathrm{APG}+\mathrm{OSE}$ & 70 & 75 & 78 \\
\hline $\mathrm{APG}+\mathrm{MOSE}$ & 70 & 75 & 76 \\
\hline Brij $35+$ OSE & 72 & 74 & 74 \\
\hline Brij $35+$ MOSE & 77 & 78 & 78 \\
\hline T-Maz $60+$ OSE & 70 & 73 & 74 \\
\hline T-Maz $60+$ MOSE & 86 & 88 & 95 \\
\hline
\end{tabular}




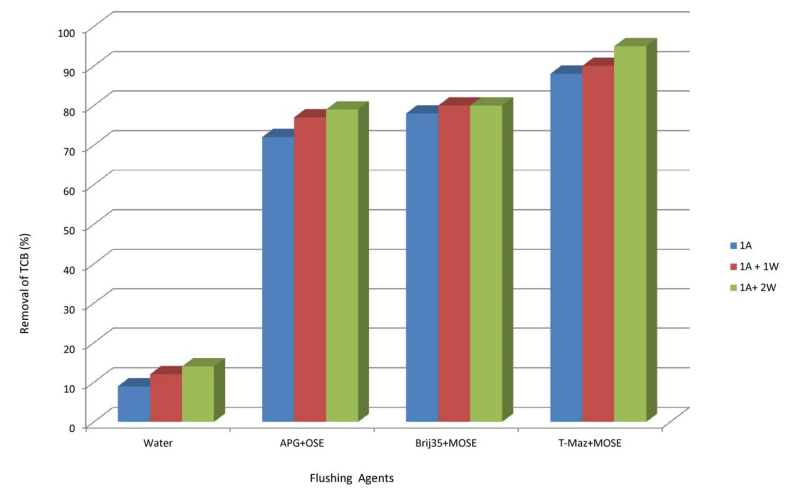

Fig. 1. The results of the TCB removal (\%) in the shaker table and centrifugation experiments.

observe phase separation in this study.

\subsection{Shaker table agitation / centrifugation experiments}

Generally, removal of the TCB was found to increase with the number of washes and rinses. However, the greatest removal occurred with the mixture of surfactant and bioactive agent, and subsequent rinses with deionized water resulted in little additional removal (Fig. 1). The highest recovery of the TCB was $95 \%$ which was obtained by the using the mixture agent (T-Maz $60+$ MOSE) (Fig. 1). Results of these experiments were compared to pure water results (Fig. 1). Mixtures of two different agents often show a "synergistic" interaction (Rosen, 1989; Lee, 1999; Lee et al., 2001). Mixed micelle formation in aqueous solution can be greater than that of the individual components, and explained by non-ideal solution theory and molecular environments $(\mathrm{pH}$, temperature, and ionic strength of the solution) (Harwell, 1992). Attwood and Florence (1983) provided a partial explanation as stated: "a cosolubilization effect where one solubilizate causes structural alterations in the micelle so enhancing its capacity for another."

Encouraging results were achieved from laboratory demonstrations. However, as an innovative technology, there are many factors that need to be investigated with future development. Special attention needs to be paid to the selection of the most appropriate surfactant and/or bioactive agent, which are critical to the success of the implementation of the remediation process and have significant effects on the treatment costs.

\section{Conclusion}

In the shaker table and centrifugation experiment phase, the highest recovery of the TCB was $95 \%$ which was obtained by the using the mixture agent (T-Maz $60+$ MOSE). The used test methods for SESF in this study may be very useful and are essential for reducing cost and time in the SESF remediation strategies. Also, the selected mixture of the nonionic surfactant and bioactive agent can be practically used for SESF remediation of TCB contaminated soil.

\section{Acknowledgements}

We wish to acknowledge the helpful review comments and invaluable suggestions provided by Dr. Michael L. Thompson of the Department of Agronomy at Iowa State University, USA. Authors also express appreciation to the members of the Environmental Hydrogeology Laboratory, Yonsei University, Korea. This work was financially supported by the two GAIA Projects (contract number: 2013000550005 and G111-17002-0016-0), Ministry of Environment, Republic of Korea.

\section{References}

Abdul, A.S., Gibson, T.L., and Rai, D.N., 1990, Selection of surfactants for the removal of petroleum products from shallow sandy aquifers, Ground Water, 28, 920-926.

Ang, C.C. and Abdul, A.S., 1994, Evaluation of an ultrafiltration method for surfactant recovery and reuse during in situ washing of contaminated sites: Laboratory and field studies, Ground Water Monit. \& Remed., 14, 160-171.

Attwood, D. and Florence, A., 1983, Surfactant systems: Their chemistry, pharmacy and biology, Chapman and Hall, New York, 72-123.

Chu, W. and Kwan, C.Y., 2003, Remediation of contaminated soil by a solvent / surfactant system, Chemosphere, 53, 9-15.

Chung, S.-L. and Lee, D.-H., 2012, Remediation of PCE-contaminated groundwater using permeable reactive barrier system with MOM-Bentonite, J. Soil \& Groundwater Env., 17, 73-80.

Cort, T.L., Song, M.-S., and Bielefeldt, A.R., 2002, Nonionic surfactant effects on pentachlorophenol biodegrdation, Water Res., 36, 1253-1261. 
Deshpande, S., Shiau, B.J., Wade, D., Sabatini, D.A., and Harwell, J.H., 1999, Surfactant selection for enhancing ex situ soil washing, Water Res., 33, 351-360.

Fountain, J.C., Klimek, A., Beikirch, M., and Middleton, T., 1991, The use of surfactants for in-situ extraction of organic pollutants from a contaminated aquifer, J. Hazard. Mater., 28, 295311.

Harwell, H.H., 1992, Factors affecting surfactant performance in groundwater remediation applications, American Chemical Society Symposium Series, 491, 124-131.

Lee, D.-H., 1999, Experimental investigation of the removal of hydrophobic organic compounds from two Iowa soils using food grade surfactants and recovery of used surfactants, Ph.D. dissertation, Iowa State Univ., 200pp.

Lee, D.-H., Cody, R.D., and Hoyle, B.L., 2001, Laboratory evaluation of the use of surfactants for ground water remediation and the potential for recycling them, Groundwater Monit. \& Remed, 21, 49-57.

Lee, D.-H., Cody, R.D., Kim, D.J., and Choi, S., 2002, Effect of soil texture on surfactant-based remediation of hydrophobic organic-contaminated soil, Environ. Internation., 27, 681-688.

Lee, D.-H., Chang, H.-W., and Kim, C., 2008, Mixing effect of $\mathrm{NaCl}$ and surfactant on the remediation of TCB contaminated soil, Geosci. J., 12, 63-68.
Martel, R. and Gelinas, P.J., 1996, Surfactant solutions developed for NAPL recovery in contaminated aquifers, Ground Water, 34, 143-154.

Mulligan, C.N. and Gibbs, B.F., 1993, Factors influencing the economics of biosurfactants, In: Marcel Dekker (Ed.), Surfactant Science Series, Biosurfactants: production, properties and applications, vol.48, Marcel Dekker, Inc., New York, pp. 329371.

Mulligan, C.N., Yong, R.N., and Gibbs, B.F., 1999, On the use of biosurfactant for the removal of heavy metals from oil-contaminated soil, Environ. Prog., 18, 50-54.

Paria, S. and Khilar, K.C., 2004, A review on experimental studies of surfactant adsorption at the hydrophilic solid water interface, Adv. in Colloid and Interface Sci., 110, 75-95.

Rosen, M.J., 1989, Surfactants and Interfacial phenomena, John Wiley \& Sons, New York, pp. 125-431.

Rouse, J.D., Sabatini, D.A., and Harwell, J.H., 1993, Minimizing surfactant losses using twin-head anionic surfactants in subsurface remediation, Environ. Sci. \& Technol., 27, 2072-2078.

Wang, S. and Mulligan, C.N., 2004, An evaluation of surfactant foam technology in remediation of contaminated soil, Chemosphere, 57, 1079-1089. 